\title{
Measuring Librarian Outreach and Engagement through a Time Allocation Study
}

\author{
Brian Winterman and Andrew Asher
}

abstract: Demonstrating academic libraries' contribution to institutionat outcomes and strategic initiatives can be challenging, particularly in determining what library activities can be consistently and accurately assessed in ways that empirically demonstrate librory value and impact. To address this challenge, the Indiana University Bloomington Libraries onducted a time allocation study to quantify the activities of public services librarians with the god of illustrating new ways to measure their contributions that are more standardized and methodologically rigorous. This report gives an overview of the Librarian Activity Project (LAF, including preliminary findings, and offers recommendations for other institutions interested in developing their own study.

\section{Introduction}

W hat do academ Clibrarians do? Why does their work matter? The answer to the first question largely depends on who is asked. The public would likely strugglear describe a librarian's work beyond vague notions of helping people find a bogk. Even people within the academic community (students, instructors, administratord and the like) might have a limited understanding of the breadth and depth of likrarian work. Libraries often have mission statements describing what they do as a group, broadly; position descriptions explaining what they do individually; and periøic performance reports summarizing what individual librarians did. Mission statenfents, however, are too vague to adequately explain our work, and the others are largely internal documents. While libraries often produce annual reports and communications such as newsletters that highlight their accomplishments and initiatives for campus stakeholders, these statements may have limited readership and often present content that is more exceptional than representative. Common misperceptions about librarians and libraries only compound the problem. Finally, librarians themselves, when asked 
to describe their work, may explain what they want to do or should do, rather than the duties on which they spend the most time.

The second question regarding why librarian work matters is, of course, central to the Association of College and Research Libraries 2010 Value of Academic Libraries report. ${ }^{1}$ It emphasizes the importance of libraries establishing well-defined measures that address institutional outcomes related to "student enrollment, student retention and graduation rates, student success, student achievement, student learning, student engagement, faculty research productivity, faculty teaching, service, and overarching

A complete picture of academic librarian activities may help to illuminate what can be measured and how they can be evaluated, and thus which tasks can be directly linked to impact on institutional outcomes. institutional quality." Many academic librarians believe and assert that their efforts haxe impact in these areas, but effectively demonstrating these effects is challenging Also, to link what librarians think they doror could do) directly to these areas, it is essential to first know exactly how librarians spend their days at a more detailed level. A Oomplete picture of academic librarian acivities may help to illuminate what can bemeasured and how they can be evaluaten, and thus which tasks can be directly iliked to impact on institutional

outcomes. In other words, before libraries can takgon the challenge of answering why librarian work matters, they must gain a better empirical understanding of what they do.

What do librarians accomplish on a daygo-day basis to address library and institutional outcomes that is not currently recotded? Which activities might be measurable in a way that illustrates a new aspect of value and impact? This report will describe a study at Indiana University Bloomington (II) B) called the Librarian Activity Project (LAP) that was designed to provide a starting point for answering those questions.

\section{Assessment Efforts at Indiana University Bloomington}

One of the main mptivations for developing a focused empirical study of how IUB is

High-level aggregate statistics routinelyoollected and reported, such as total reference transactions or instruction sessions, may not adequately represent the depth and breadth of librarian activities and may fail to demonstrate their impact. librarians spend their time was a sense that the high-level aggregate statistics routinely collected and reported, such as total reference transactions or instruction sessions, may not adequately represent the depth and breadth of librarian activities and may fail to demonstrate their impact. Like many academic libraries, IUB has seen a steady and dramatic decline in reference questions over the past decade-a decrease of 54 percent between 2013 and 2018 and a drop of 77 percent since $2008 .^{2}$ This downward trend may be due to increased availability of reference texts and information

via the Internet, as well as to gradual closures and consolidations of small branch and 
departmental libraries, resulting in fewer reference desks. Despite this downturn, IUB librarians do not believe they spend less time on reference activities; instead, they think they devote equal time to fewer, more difficult, and more time-consuming questions. Such challenging inquiries may even have greater impact on the research outcomes of our constituents.

Although total instruction sessions recorded at IUB have remained relatively stable, these figures may hide the scope of librarians' work. For example, pedagogical approaches to information literacy have shifted away from one-shot instruction sessions toward assignment design, curricular integration, faculty-librarian collaboration, and use of unique and primary materials. These changes likely resulted in a net decrease in aggregate instruction totals. But these higher-impact activities are more time-consuming for librarians, and a stable instruction figure might indicate much more

Pedagogical approaches to information literacy have shifted away from one-shot instruction sessions toward assignment design, curricular integration, facultylibrarian collaboration, and use of unique and primary materials.

time spent on these tasks. In fact, a decrease might, in this ease, signify a more successful program of teaching information literacy.

Nevertheless, it is often difficult to argue the the impact and value of libraries and librarians have increased when two principal metrics remain static or trend downward. By using a time allocation methodology, the AP was designed to provide empirical data about how librarians use their time in service to the research and educational missions of the university as well as an addirional measure focused more on effort and impact than on simple aggregate counts.

\section{Piloting (Time Allocation Study: Lessons Learned}

Since the IUB Libraries had never attempted a time allocation study of librarians, we began with an infermal pilot study to attempt to capture data on librarian activities. The pilot projectalso informed and helped to refine the development of data collection categories, tools, and procedures. In 2017, the authors asked six librarians who worked primarily in public services to log their activities during a workday. Most recorded their inforrantion on an hourly basis. The authors then interviewed them the following day toclarify and expand upon their entries, to discuss their perceptions of a "typical" day, and to describe the work they perceived to have the most impact.

- Shortcomings in the pilot study helped the authors refine their goals and approaches for a broader, more in-depth investigation. Some weaknesses of the pilot included:

- Six participants recording one day of activity each constituted a small sample and thus made certain types of analysis impossible. More participants chronicling more days would be necessary to arrive at meaningful results.

- Few guidelines explained how participants should categorize activities and what to prioritize. Some recorded every detail of their day, while others wrote down 
only what they thought the authors might want to see. This led to inconsistencies in the quality of data collected.

- The pilot inspired apprehension not only among the participants but also among colleagues who heard about the study. People wondered who might see the data and how the information might be used. A lack of clearly stated goals for the pilot likely added to the anxiety.

- Since the authors did not intend to make the data public, they did not seek Institutional Review Board (IRB) approval for the pilot. The lack of IRB consent may have had a negative effect on what activities were recorded and how they were documented because participants lacked assurance that the information woyld remain private.

\section{Expanding and Improving the Study: The Librarian Activity Rejject}

With the deficiencies of the pilot in mind, the authors redesigned mary aspects of the study, including recruitment, goals, data collection, and analysig approaches. In early 2018, all IUB librarians with public services responsibilities (approximately 40) were invited to an information and training session that described the goals and protocol of the study (see Appendix A). The stated goals included the following:

1. Quantify librarian contributions to the education and research mission of the institution.

2. Quantify librarian contributions in a way that@lows comparison with other teaching and research faculty efforts.

3. Discover new ways for librarians to demonstrate their impact on education and research at the institution.

Regarding goal number 1, the brogerest categories for activities initially consisted of "Education," "Research," and "Dther." The "Other" category included breaks as well as meetings or service duties that could not be directly tied to education or research. A fourth category called "Eultural Development" was added later to encompass such tasks as exhibits or spegial events.

Participants were asked to record "Education" and "Research" work based on the following guidelines:

Education: Activities that support or fulfill the education mission of the university may incleace instruction (for credit or not); instructional preparation; assessment of teaching, leanning, or both; consultations related to curricula, courses, or assignments; and

Educational materials or displays.

Research: Activities that support or fulfill the research mission of the university may include any original research or support of original research not associated with coursework.

Twenty-two librarians, around half of those invited, ultimately participated in the study (see Table 1). The librarians logged their daily activities for two consecutive workdays and then participated in a follow-up interview. The logging days were randomly selected, and the interviews took place on the day after logging. 


\section{Table 1.}

\section{Sample size and length of study}

$\begin{array}{lc}\text { Number of participating librarians }{ }^{*} & 22 \\ \text { Days recorded } & 44 \\ \text { Units of activity recorded } & 1,666 \\ \text { Total hours recorded } & 416.5^{*}\end{array}$

At the time of the study, 5 librarians were tenured and 17 untenured; 2 were full librarians, 8 were associate librarians, and 12 were assistant librarians?

The daily activity logs (see Appendix B) included broader yeversity mission categories (for example, education and research), more specific no. $\mathrm{k}$ categories (for example, collections, and instruction), and audience. Participants were asked to record any work during each 24-hour period using check boxes as we Pas a notes field. Each hour in the day was divided into four units so that participants could have the flexibility to report activities either by time spent or, in cases of mutitasking, by which task during that hour represented the most effort. Priority was giten to making sure that librarian activities could be examined alongside those of other teaching and research faculty regarding the mission and core values of the university.

Participants were instructed folog some activities in a manner that deviated from our normal annual review and dossier classifications. For example, teaching a class for which the librarian was the Brofessor of record was recorded as "Instruction" rather than "Service," which would formally be the case in an annual review or dossier.

The follow-up irftrviews served several purposes. The researcher reviewed the daily activity logs $w 1$ th the participant to discuss each entry and correct any mistakes, to make reporting more uniform across participants, and to identify activities that warranted discubsion in a recorded interview. Recorded interview questions mostly focused on instruftional and cultural development duties.

\section{Overview of Findings}

Activity logging and interviews occurred from January through May 2018. Afterward, the recordings were transcribed and coded, and the research team analyzed the 44 daily activity logs. Overall, the study produced a rich data set that provides many opportunities for different types of analyses. Table 2 and Figure 1 present a few of the findings from the quantitative data. The full results will be published soon. 


\section{Table 2.}

\section{Time librarians at Indiana University Bloomington spent on activities}

\begin{tabular}{lccc}
\hline Activity & Units recorded & Hours & Percentage of activity \\
\hline Education & 637 & 159.25 & $38.2 \%$ \\
Research & 348 & 87 & $20.9 \%$ \\
Cultural development & 84 & 21 & 5 \\
Other & 598 & 149.5 & \\
& & & $35 \%$ \\
\hline
\end{tabular}

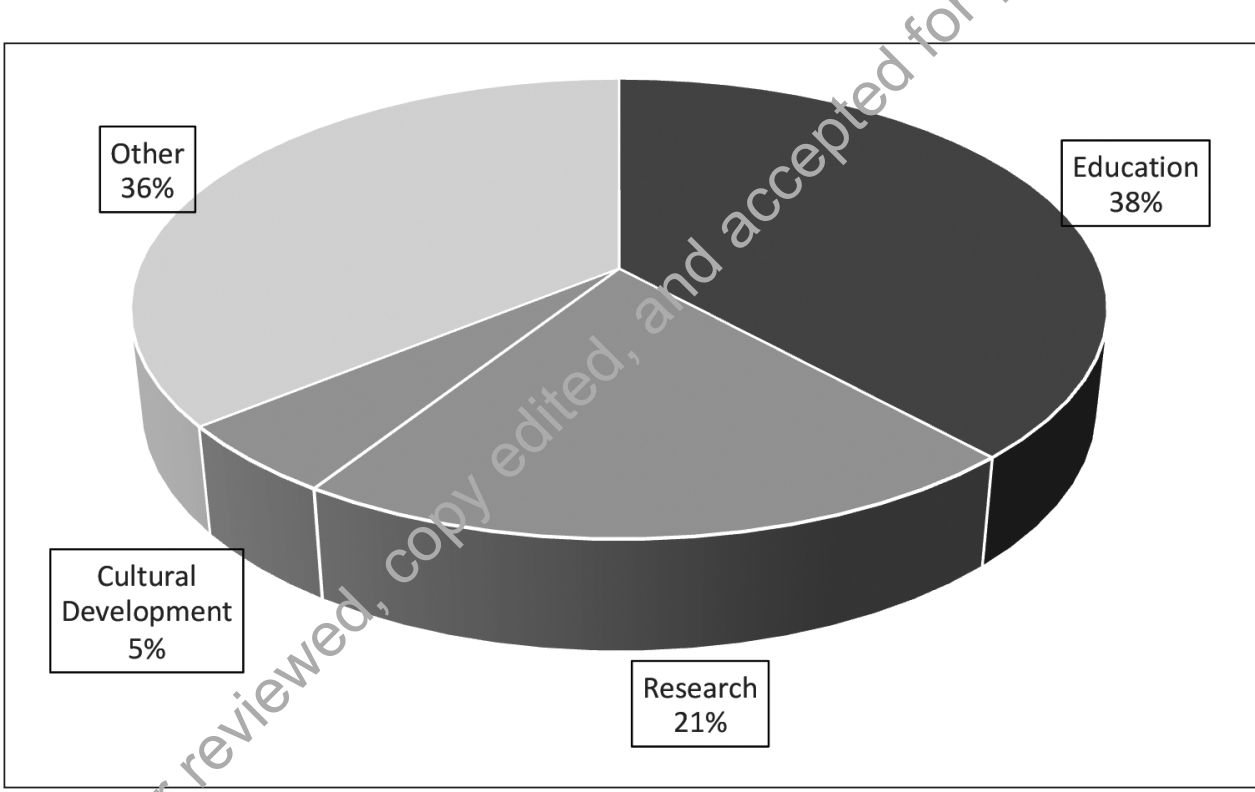

Figure 1 forportion of librarians' time spent on core activities at Indiana University Bloomington.

\section{Discussion}

The expanded LAP study represented clearer goals, broader participation, and significantly more data collection than the pilot did. Most participants seemed enthusiastic about the study. They were diligent and thorough in their recording, and they readily shared additional information in follow-up interviews. Their willingness and enthusiasm greatly improved the quality of data collected, and their excitement to see and discuss the results indicated a potential to do further work from the study. Conversations continue 
at IUB regarding what has been learned, next steps, and how this type of investigation might help IUB librarians communicate with stakeholders. For now, the authors are satisfied that three goals were met:

Goal 1. Quantify librarian contribution to the education and research mission of the institution. By abandoning some of the traditional internal classifications of librarian work and focusing on the university mission, a new "big picture" of librarian contributions emerged. The breakdown of activities illustrated in Table 2 and Figure 1 shows that the majority of librarian work is clearly and directly related to the mission of the university. In addition, much of what was classified as "Other" could also be tied to the mission, if less directly. This broad view of librarian work could be useful in communicating librarian contributions externally. For example, the time spent on "Education" (38.2 percent) is particularly noteworthy. External audiences might be surprised to learn that much of librarians' work on education involves directly engaging with students and instructors on all aspects of the curriculum, including assignment design, class planning, teaching, and follow-up constiffations. Furthermore, the work in this categrory is no longer dominated by teaching libraby basics to large groups of students in iftroductory composition classes. Rather, many instructional By abandoning some of the traditional internal classifications of librarian work and focusing on the university mission, new "big picture" of Hibrarian contributions enierged.

\section{Much of librarians' work on education involves directly engaying with students and instructors on all aspects of the curriculum, including assign- ment design, class planning, teaching, and follow-up consul- tations.} collaborations are ongoing find in-depth, and they represent rich partrerships cultivated over time. This more detailed view of the work is, of course, important to examine on its own, but for many external audiences, the "big picture" Nill serve as the gateway to that more granular view.

Goal 2. Quantify librarian contribution in these areas in a way that allows comparison with the efforts of other teaching and research faculty. The authors examined results from time allocation studies of other university faculty, but the results from the most robugestudies were difficult to compare to the LAP findings. It was not always clear in the other studies how activities were classified and how they compared to librarian work. Generally, librarians spend as much or more time as other faculty on "Education," but much less time on "Research." The LAP results could prove useful for campus conversations regarding faculty matters. For example, librarians at

Generally, librarians spend as much or more time as other faculty on "Education," but much less time on "Research." IUB are eligible for tenure, and discussions about policies and standards occasionally require clarification of how librarians differ from other faculty. Perhaps this analysis could better illustrate how librarians stand apart from other instructors as well as what both groups have in common. 
Goal 3. Discover new ways for librarians to demonstrate their impact on education and research at the institution. At this time, the authors have not identified any new activities that they feel could be quantified on a regular basis to better demonstrate our impact. In fact, this study helped to show that much librarian work is difficult to describe effectively with static, time-specific quantities. As stated earlier, traditional measures, such as instruction or reference statistics, do not capture the full picture of effort and impact. Falling instruction statistics, for example, might indicate that some librarians teach fewer classes but put more effort into the sessions they do lead. The LAP data and interview transcripts support this conclusion. For example, one LAP participant spent only a quarter of the instructional time teaching. The rest was devoted to communicating with the instructor, preparing assignments or materials, and follow-up with students. So, some librarian activities might better be described through a combination of qualitative and quantitative information collected over time with more context.

\section{Recommendations}

The authors learned much from both the pilot and the expanded LAP study and offer the following recommendations for institutions considering (a) similar initiative:

1. Some of these approaches could certainly be use (a) 10r small organizations or departments, but a larger sample size is essentialo certain types of assessment, particularly statistical analysis. Having fewer participants might be balanced out by tracking activities for more days, but it dependson the goals. Make sure you have an adequate sample to match your objectives.

2. Participant attitude makes a differefnee in the quality of data collected and the participation rate itself (assuming articipation is not mandatory). The expanded LAP study was more successful partly @ecause it was IRB-approved, and therefore participants knew that their individual results would remain private. Another factor in its success was that the research teampent significant time explaining the study to participants and setting clear expectations and guidelines about how the data would be used. Also, having clearly stated go alls that seemed beneficial or interesting to potential participants probably helped in recruitment.

3. Consider starting small. The expanded LAP project took a significant amount of time and energy. It might be more appropriate to test your project with a pilot.

Much information about what librarians do every day goes undocumented. A study like the Librarian Activity Project can measure librarians' efforts in new ways to enable comparison with other teaching and research faculty and to disclose librarians' Contribution to the goals of their institution. The results of such an investigation might help librarians communicate their value and impact to stakeholders.

Brian Winterman is an information literacy and assessment librarian at the Herman B Wells Library of Indiana University in Bloomington; he may be reached by e-mail at: bwinterm@ indiana.edu.

Andrew Asher is an assessment librarian at the Herman B Wells Library of Indiana University in Bloomington; he may be reached by e-mail at: asherand@indiana.edu. 


\section{Appendix A}

\section{Indiana University Bloomington Librarian Activity Project, spring 2018}

\section{Broad Goals}

1. Quantify librarian contribution to the education and research mission of the institution.

2. Quantify librarian contribution in these areas in a way that allows comparison with other teaching and research faculty efforts.

3. Discover new ways for librarians to demonstrate their impact on education and research at the institution.

\section{Instructions}

1. Begin recording activities when you begin your workday and continue until you have finished your day.

2. Each hour is divided into four parts. These do not representexact 15-minute increments; rather, they are there to estimate what portion of the time in that period was spent on what activity, category, and audience.

Example: If you have a one-hour meeting at 8 anchat concerns supporting teaching for undergraduates and supporting research for graduate students, with some of the work being part of your instruction responsipinties and some part of other performance responsibilities, you might fill out the form ine this:

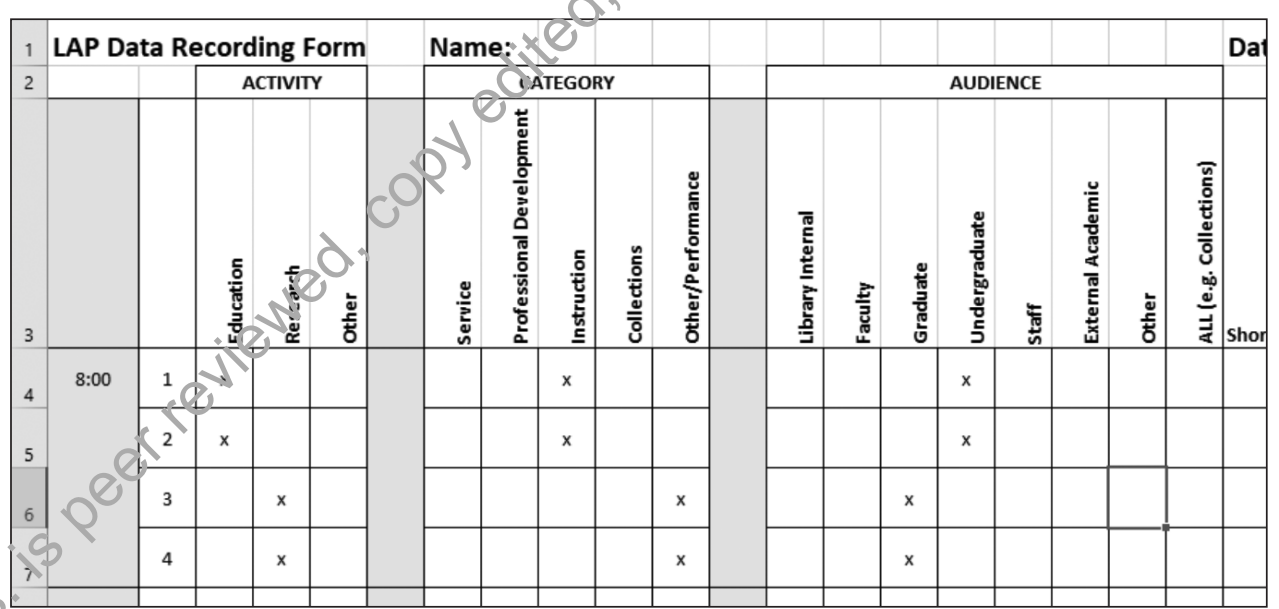

3. In some cases you may "select all that apply," though please think in terms of primary activity, category, and audience.

4. Note: Audience is not necessarily who you are spending the time with, but who the primary beneficiary of the effort is; e.g., for a meeting with librarians to discuss instruction for undergraduates, the audience would be undergraduates not library internal. Think in terms of the result of the effort. 
5. Add a short description of the activity. These will serve as prompts for us to glean more detail in follow-up interviews if necessary.

6. Bring both completed forms with you to the follow-up interview.

\section{Activity Guidelines}

Education: Activities that support or fulfill the education mission of the university may include instruction (for credit or not), instructional preparation, teaching and / or learning assessment, consultations related to curricula, courses, or assignments, educational materials or displays, etc.

Research: Activities that support or fulfill the research mission of the university may include any original research or support of original research not associated with coursework.

\section{Appendix B}

Daily Activity Log for the Librarian Activity Project

\begin{tabular}{|c|c|c|c|c|c|c|c|c|c|c|c|c|c|c|c|c|c|c|c|c|}
\hline & & & & \multicolumn{4}{|c|}{ ACTIVITY } & \multicolumn{6}{|c|}{ CATEGORV } & \multicolumn{7}{|c|}{ AUDIENCE } \\
\hline Subject & Date & Hour & & & 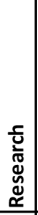 & 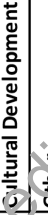 & & 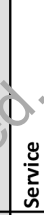 & 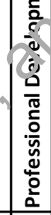 & 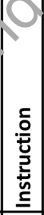 & 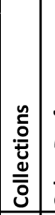 & 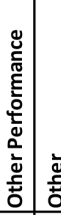 & & 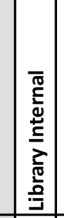 & 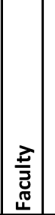 & 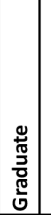 & & & & 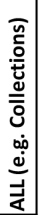 \\
\hline 01 & $2 / 28 / 2018$ & 5:00 & 1 & & & & & & & & & & & & & & & & & \\
\hline 01 & 2/28/2018 & 5:00 & 2 & & & & & & & & & & & & & & & & & - \\
\hline 01 & $2 / 28 / 2018$ & 5:00 & 3 & & & & & & & & & & & & & & & & & \\
\hline 01 & $2 / 28 / 2018$ & $5: 00$ & 4 & & & & & & & & & & & & & & & & & 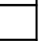 \\
\hline 01 & $2 / 28 / 2018$ & 6:00 & I & & & & & & & & & & & & & & & & & \\
\hline 01 & $2 / 28 / 2018$ & $6: c 9$ & 2 & & & & & & & & & & & & & & & & & \\
\hline 01 & 2/28/2018 & (5:000 & 3 & & & & & & & & & & & & & & & & & \\
\hline 01 & 2/28/2018 & 6:00 & 4 & & & & & & & & & & & & & & & & & \\
\hline 01 & $2 / 28 / 2110$ & $7: 00$ & 1 & & & & & & & & & & & & & & & & & \\
\hline 01 & $2 / 2 / 2018$ & $7: 00$ & 2 & & & & & & & & & & & & & & & & & \\
\hline 01 & $2 / 28 / 2018$ & $7: 00$ & 3 & & & & & & & & & & & & & & & & & \\
\hline 01 & $2 / 28 / 2018$ & 7:00 & 4 & & & & & & & & & & & & & & & & & \\
\hline GD & $2 / 28 / 2018$ & $8: 00$ & 1 & & & & & & & & & & & & & & & & & \\
\hline 01 & 2/28/2018 & $8: 00$ & 2 & & & & & & & & & & & & & & & & & \\
\hline 01 & $2 / 28 / 2018$ & $8: 00$ & 3 & & & & & & & & & & & & & & & & & \\
\hline 01 & $2 / 28 / 2018$ & $8: 00$ & 4 & & & & & & & & & & & & & & & & & \\
\hline 01 & $2 / 28 / 2018$ & 9:00 & 1 & & & & & & & & & & & & & & & & & \\
\hline 01 & $2 / 28 / 2018$ & 9:00 & 2 & & & & & & & & & & & & & & & & & \\
\hline 01 & $2 / 28 / 2018$ & 9:00 & 3 & & & & & & & & & & & & & & & & & \\
\hline 01 & $2 / 28 / 2018$ & 9:00 & 4 & & & & & & & & & & & & & & & & & \\
\hline 01 & $2 / 28 / 2018$ & 10:00 & 1 & & & & & & & & & & & & & & & & & \\
\hline 01 & $2 / 28 / 2018$ & 10:00 & 2 & & & & & & & & & & & & & & & & & \\
\hline 01 & $2 / 28 / 2018$ & 10:00 & 3 & & & & & & & & & & & & & & & & & \\
\hline$n$ & $2 / 70 / 7910$ & $1 n \cdot \mathrm{nn}$ & $\frac{1}{1}$ & & & & & & & & & & & & & & & & & \\
\hline
\end{tabular}




\section{Notes}

1. Megan Oakleaf, The Value of Academic Libraries: A Comprehensive Research Review and Report (Chicago: Association of College and Research Libraries, 2010), 12.

2. Andrew Asher, "Who's Asking What? Modelling a Large Reference Interaction Dataset," in Proceedings of the 2014 Library Assessment Conference: Building Effective, Sustainable, Practical Assessment, ed. Sarah Durso, Steve Hiller, Martha Kyrillidou, and Angela Pappalardo (Washington, DC: Association of Research Libraries, 2015), 52-62, http:/ / libraryassessment.org/bm doc/ proceedings-lac-2014.pdf. 


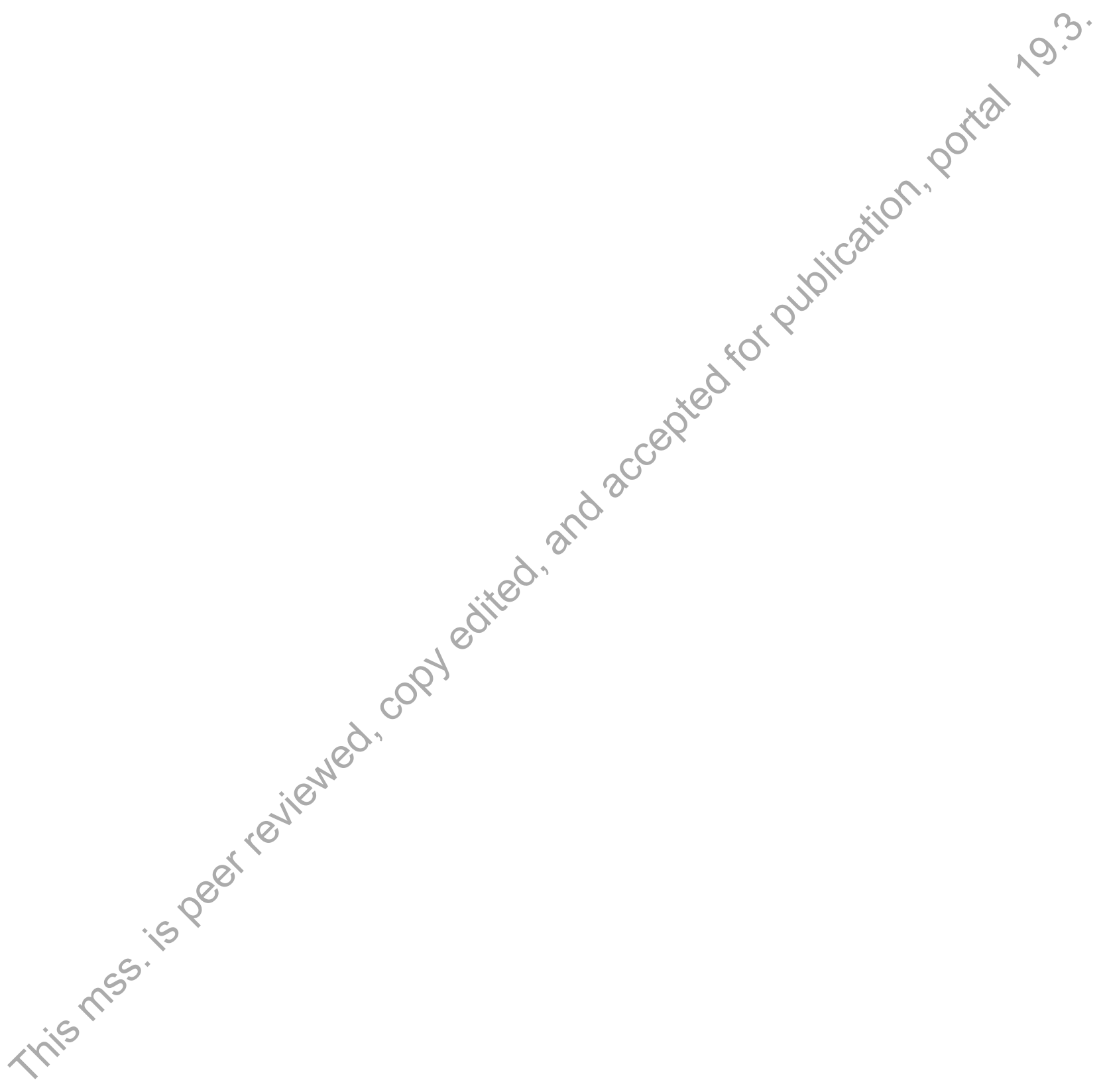

